\title{
SZKOŁA, UNIWERSYTET I BIZNES JAKO WEZZŁY SIECI UCZĄCEJ SIĘ - ROLA PRZYSZKOLNYCH OGRÓDKÓW METEOROLOGICZNYCH W KSZTAŁCENIU GEOGRAFICZNYM I PRZYRODNICZYM W SZKOLE PODSTAWOWEJ „ŁEJERY” W POZNANIU
}

\author{
JAKUB SYPNIEWSKI ${ }^{1}$, SEBASTIAN KENDZIERSKI ${ }^{2,3}$ \\ ${ }^{1}$ Uniwersytet im. Adama Mickiewicza w Poznaniu, Wydział Nauk Geograficznych i Geologicznych, \\ ul. B. Krygowskiego 10, 61-680 Poznań \\ ${ }^{2}$ Uniwersytet im. Adama Mickiewicza w Poznaniu, Wydział Nauk Geograficznych i Geologicznych, \\ ul. B. Krygowskiego 10, 61-680 Poznań \\ ${ }^{3}$ ENEA Trading Sp. z o.o. \\ Świerże Górne, gmina Kozienice, 26-900 Kozienice 1
}

\begin{abstract}
Geography is traditionally perceived as a discipline of science dealing with the spatial diversity of the outer shell of the earth, and the relations between its components and human activity (Tkocz, 2005). The identification of relations and correlations, constructing hypotheses and, finally, observations and measurements are among the most important skills of applying knowledge in practice (Regulation of the Ministry of Education of 14 February 2017 on the core curriculum). In a world of dynamic acquisition of factual knowledge, practical skills are gaining in importance, together with the ability to select information and search for it. Connectivity is the answer to contemporary trends in education, viewed as the theories of education, perceiving knowledge as a set of network connections between objects. In this perspective, learning is about establishing and developing such connections (Downes, 2017). This idea promotes abstaining from fact-based knowledge or even concept development and to look for facts, collect and process them. As part of "Łejery! What kind of weather is this?!" carried out by the school (project organizer), Faculty of Geographic and Geological Sciences (the content-related sponsor) and the Enea company (sponsor of the Enea Academy of Talents project), a self-organising map was created in accordance with the theory of constructivism. By means of measurements and exchanging information, the students can empirically and single-handedly acquire their own knowledge and practical skills.
\end{abstract}

Keywords: connectivity, education, Łejery, weather measurements, weather station, Poznań

\section{WSTĘP}

Obserwowana współcześnie presja, jaką środowisko cyfrowe wywiera na szkołę, stwarzając uczniom atrakcyjną alternatywę rozwoju (Dylak 2013), sprawia, że dotychczasowy dylemat edukacyjny „wiedzieć jak” (know-how) czy „wiedzieć co" (know-what) coraz częściej jest zastępowany przez „wiedzieć gdzie" (know-where). Oznacza to, że wiedza o tym, gdzie znaleźć potrzebne informacje, jest ważniejsza niż znajomość tych informacji (Frankowski 2015). W ostatniej zmianie organizacyjnej (Czachorowski 2017) w polskim systemie 
edukacji podkreśla się zdecydowane odejście od metod podających i przejście do kształcenia poszukującego (Rozporządzenie MEN z dnia 14 lutego 2017 r. w sprawie podstawy programowej). Jako jeden z ogólnych celów kształcenia w zakresie umiejętności i stosowania wiedzy w praktyce akcentuje się prowadzenie obserwacji i pomiarów w terenie, analizowanie, dokonywanie opisu, klasyfikowanie. Pozyskiwanie przez uczniów danych pomiarowych z wykorzystaniem aparatury meteorologicznej zlokalizowanej w formie przyszkolnego ogródka meteorologicznego, a następnie ich opracowanie i analiza z jednej strony pozwala na kształtowanie podstawowych kompetencji, charakterystycznych dla takich nauk jak geografia czy przyroda, z drugiej zaś umożliwia lepsze poznanie najbliższego regionu życia uczniów.

\section{CEL PRACY, METODY BADAŃ}

Realizacja zapisów dokumentów, które regulują program nauczania szkół, zarówno w Polsce (Rozporządzenie MEN z dnia 14 lutego 2017 r. w sprawie podstawy programowej), jak i międzynarodowych zaleceń (Rocard report 2007) zachęca do poszukiwania nowych rozwiązań w kształceniu geograficznym w szkole podstawowej. $Z$ kolei ponadregionalna presja konwergencji programów nauczania (Rundgren 2016) różnych państw europejskich wywierana przez międzynarodowe, standaryzowane testy wiedzy i umiejętności (np. PISA), paradoksalnie służy popularyzacji nauczania opartego o naukowe dociekanie uczniów, które w szczególny sposób angażuje w proces kształcenia. Celem pracy jest ocena możliwości wykorzystania przyszkolnego ogródka meteorologicznego w kształceniu geograficznym i przyrodniczym w szkole podstawowej. Analizie poddano dokumenty regulujące proces kształcenia, w tym zapisy nowej podstawy programowej kształcenia ogólnego. Dzięki obserwacji uczestniczącej możliwa stała się analiza powstawania sieci uczącej się zgodnej z założeniami konektywistycznej teorii procesu kształcenia oraz ocena sposobów wykorzystania danych pomiarowych, zarówno na lekcjach geografii, jak i przyrody. $\mathrm{W}$ przyszłości planowane jest także wykorzystanie danych pomiarowych w toku zajęć z innych przedmiotów, m.in. matematyki czy informatyki.

\section{Konektywizm w kształtowaniu geograficznym}

Współczesne teorie pedagogiczne (ryc. 1), takie jak behawioryzm, kognitywizm i konstruktywizm, chociaż niewątpliwie odniosły wysokie osiągnięcia, stały się niewystarczające w czasach, gdy uczenie się uległo przekształceniu w obszar aktywności nieformalnej, sieciowej i technologicznej (Siemens 2005). Pojmowanie uczenia się wychodzącego naprzeciw potrzebom edukacji 


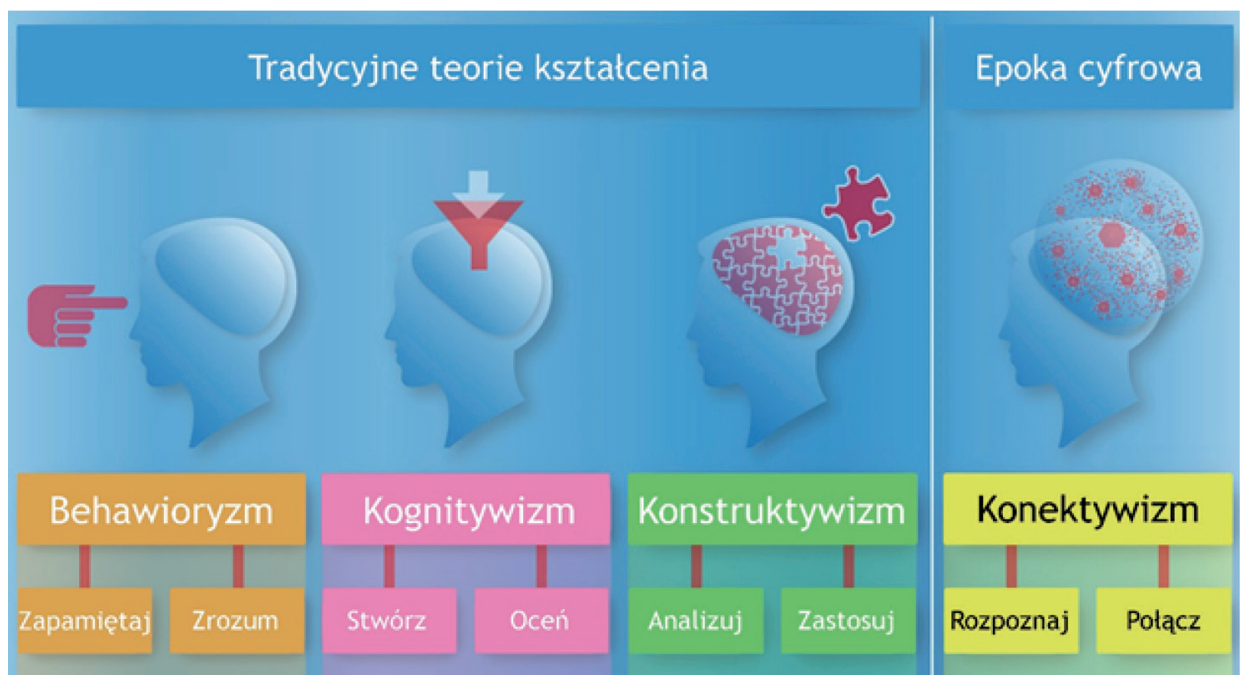

Ryc. 1. Teorie kształcenia

Źródło: <http://www.jankowskit.pl/kognitywistyka/teorie-uczenia.html> [dostęp: 27.03.2018] (tłum. J. Sypniewski)

Fig. 1. Theories of education.

w globalnej sieci technologii i wiedzy, zdaniem Stephena Downesa i George'a Siemensa, wymaga reorganizacji postrzegania procesu kształcenia oraz samej nauki. Autorzy pojęcia „konektywizmu” w nauczaniu postrzegają wiedzę jako zbiór połączeń sieciowych pomiędzy poszczególnymi obiektami, a uczenie się jest $\mathrm{w}$ tej perspektywie tworzeniem i rozwijaniem takich połączeń (Downes 2017). Realizacja wyznaczonych celów odbywa się w wyniku osobistych doświadczeń ucznia. Dominuje zatem, zgodnie z podziałem Klus-Stańskiej (2000) odwołującym się do kryterium samodzielności ucznia, przyswajanie wiedzy „W poszukiwaniu śladu” zamiast „po śladzie”. Uczenie się pojmowane jako podłączenie do sieci nie ma początku i końca. Oznacza to, że kurs konektywistyczny zaprojektowany jest jako sieć, gdzie zamiast czytać, uczestnicy współdziałają ze sobą. Nie skupiają się na [przyswajanych] treściach nauczania, ale na pracy z nimi, przetwarzaniu i publikowaniu w środowisku [uczącym się], które stymuluje podejście badawcze (Downes 2017).

\section{„Łejery! Co to za pogoda?!” - projekt sieci uczącej się}

W ramach projektu „,ejery! Co to za pogoda?!”, prowadzonego przy udziale trzech podmiotów (węzłów sieci uczącej się):

1. szkoły - organizatora projektu, 
2. Wydziału Nauk Geograficznych i Geologicznych Uniwersytetu im. Adama Mickiewicza w Poznaniu - patrona merytorycznego przedsięwzięcia oraz

3. Enea S.A. - sponsora programu grantowego dla szkół „Enea Akademia Talentów",

stworzono sieć uczącą się, zgodną z założeniami teorii konektywizmu. Sieć taka jest zbiorem podmiotów, z których każdy jest jednocześnie nadawcą i odbiorcą informacji, ponieważ wiedza może znajdować się w zasobach poza nami i dopiero połączenie się z tymi zasobami czy bazami uruchamia proces uczenia się (Frankowski 2015).

Głównym celem projektu była aktywizacja i integracja społeczności szkolnej (uczniów, nauczycieli, rodziców) oraz partnerów zewnętrznych (UAM, Enea) przez pogłębianie wiedzy na temat środowiska geograficznego, jego ochrony oraz wpływu człowieka na zmiany klimatu dzięki zorganizowaniu profesjonalnego ogródka meteorologicznego oraz realizacji cyklu warsztatów z zakresu nauk przyrodniczych i meteorologii. Uczniowie w wyniku wspólnych obserwacji i doświadczeń zyskali możliwość konstruowania własnej wiedzy i rozwijania lub doskonalenia umiejętności praktycznych. Rzeczywisty proces sieciowania rozpoczął się znacznie wcześniej, tj. na etapie konsultacji z przedstawicielami uniwersytetu. Konsultacje te dotyczyły parametrów aparatury, o której finansowanie starała się szkoła, przygotowując wniosek o grant. Po uzyskaniu pozytywnej oceny rozpoczął się drugi etap pozyskiwania grantu - internetowa prezentacja połączona z głosowaniem. Uczniowie Szkoły Podstawowej nr 83 , Łejery” im. Emilii Waśniowskiej w Poznaniu, beneficjenci grantu, przygotowali animację poklatkową. Ukazano w niej projekt i realizację wyposażenia przyszkolnego ogródka meteorologicznego (https://www.youtube.com/watch? $\mathrm{v}=$ maKFyPDz3IA).

Uczenie się podmiotów we wzajemnej sieci powiązań pokazano na rycinie 2. Liniami oznaczono połączenia, z których dłuższa oznacza, co dany węzeł oferuje pozostałym, do których jest przyłączony. Patrząc w taki sposób na przedstawiony diagram, można zauważyć, że np. szkoła „Łejery” umożliwia uniwersytetowi odbywanie studenckich praktyk pedagogicznych, sama zaś jest jego beneficjentem w kontekście organizowanych wydarzeń popularyzujących naukę, jak chociażby coroczny Festiwal Nauki i Sztuki czy Noc Naukowców. Ważne połączenia stanowią linie, które dotychczas nie pojawiały się w tego typu sieciach - po raz pierwszy szkoła oferuje uniwersytetowi oraz IMGW-PIB swoje dane pomiarowe, które są zbierane dzięki profesjonalnej aparaturze znajdującej się w ogródku meteorologicznym.

\section{Wykorzystanie ogródka meteorologicznego w nauczaniu}

Głównym celem projektu w ramach grantu było zbudowanie przyszkolnego ogródka meteorologicznego z oprzyrządowaniem pozwalającym na ciągłą 


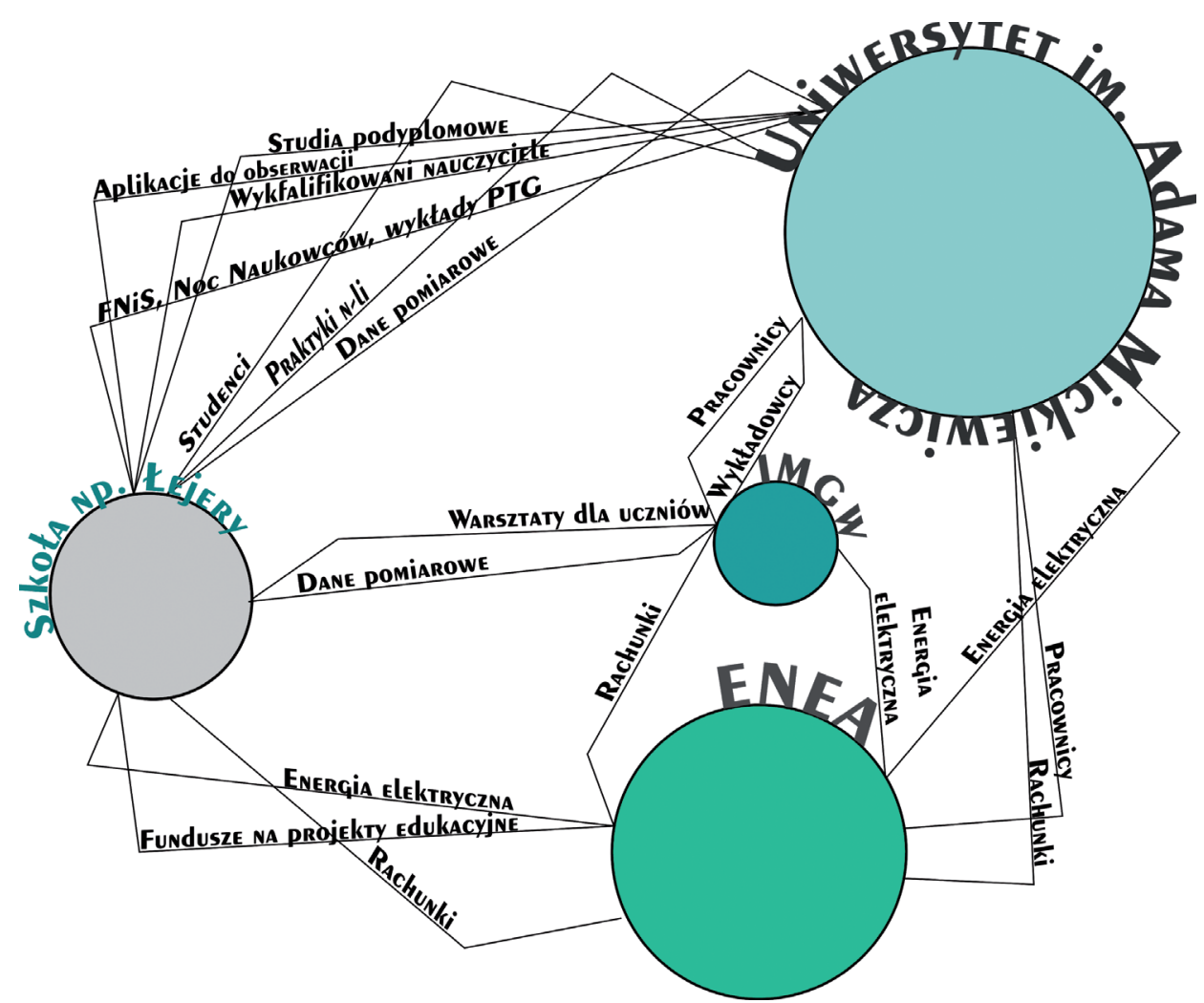

Ryc. 2. Sieć ucząca się trzech węzłów: szkoły, uniwersytetu i partnera biznesowego na przykładzie projektu „Łejery! Co to za pogoda?!” (oprac. J. Sypniewski)

Fig. 2. School, university and business as learning network nodes based on the example of the project "Lejery! Co to za pogoda?!"

obserwację stanu pogody. Ogródek meteorologiczny znajduje się w centralnej części Poznania, na północ od parku Cytadela przy Szkole Podstawowej nr 83 „Łejery” w Poznaniu. Na jego wyposażeniu znajdują się standardowe przyrządy meteorologiczne, używane w sieci pomiarowej Instytutu Meteorologii i Gospodarki Wodnej - Państwowego Instytutu Badawczego (IMGW-PIB). Podstawowym elementem wyposażenia ogródka meteorologicznego jest klatka meteorologiczna, w której znajdują się zestawy termometrów: termometr suchy oraz "zwilżony" (psychrometr Augusta), a także termometry ekstremalne (minimalny i maksymalny). Umieszczono w niej również barometr do pomiaru ciśnienia atmosferycznego oraz zapasowy termometr. Najważniejszym jednak urządzeniem pomiarowym jest automatyczna stacja meteorologiczna typu DAVIS Vantage Pro2, zakupiona w ramach projektu grantowego. W jej skład wchodzi system czujników zewnętrznych do pomiarów temperatury powietrza, wilgotności 
względnej, ciśnienia atmosferycznego, prędkości i kierunku wiatru, opadów atmosferycznych oraz kalkulacji parametrów pochodnych, tj. temperatury punktu rosy, temperatury odczuwalnej i ewapotranspiracji. Na terenie ogródka znajduje się również poletko termometrów gruntowych (ryc. 3).

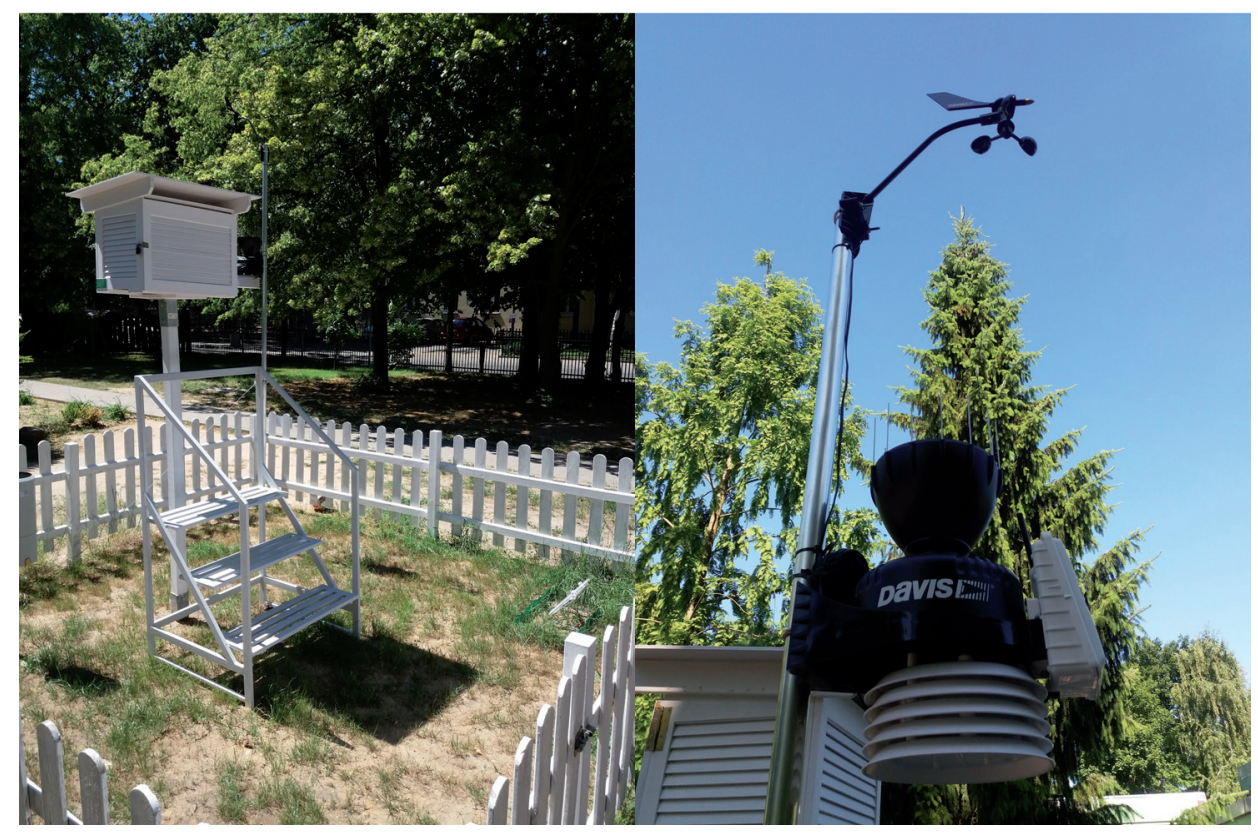

Ryc. 3. Przyszkolny ogródek meteorologiczny przy Szkole Podstawowej nr 83 „Łejery” w Poznaniu (fot. J. Sypniewski)

Fig. 3. Meteorological station near Primary School No. 83 "Łejery" in Poznań

Idea budowy przyszkolnego ogródka meteorologicznego wspomaga proces nauczania przez realizację efektów kształcenia zapisanych w nowej podstawie programowej do nauczania przyrody i geografii w szkole podstawowej. W planowaniu lekcji powinno uwzględnić się czynności ucznia od odczytywania wartości pomiaru składników pogody, stosując właściwe jednostki, po bezpośrednie ich obserwacje. Następnie, po zebraniu i zapisaniu danych, uczeń może analizować ich wyniki oraz dostrzegać zależności między nimi. Bezpośrednie pomiary meteorologiczne, prowadzone w najbardziej zbliżonych do profesjonalnych (np. sieci pomiarowej IMGW-PIB) warunkach, uczą systematyczności i dokładności wykonywanych pomiarów.

Wykorzystując psychrometr Augusta, składający się z zestawu suchego i „zwilżonego" termometru, uczniowie odczytują wartości wilgotności względnej z tablic psychrometrycznych. Dla kombinacji wartości temperatury powietrza z dwóch termometrów dokonuje się odczytu danej wilgotności względnej. 
Kolejnym elementem mierzonym w ogródku jest opad atmosferyczny. Pomiar przeprowadzany jest według instrukcji Światowej Organizacji Meteorologicznej (WMO). Obserwator o godzinie 6.00 czasu uniwersalnego, przy użyciu deszczomierza Hellmana, określa wysokość opadu za ostatnią dobę (WMO, 2015). Następnie zapisuje odczytaną wartość w dzienniczku opadowym. Obserwator odczytuje również minimalną i maksymalną wartość temperatury powietrza za ubiegłą dobę z termometru odpowiednio: minimalnego i maksymalnego. W przypadku termometru minimalnego następuje przygotowanie urządzenia do kolejnego pomiaru (zbicie temperatury).

Opisane czynności ucznia doskonalą umiejętność obserwacji poszczególnych składników środowiska, a po zebraniu danych także ich porównywanie, opisywanie i klasyfikowanie. Dysponując dłuższą serią pomiarową uczniowie mogą porównywać zbierane przez siebie dane z innymi seriami pomiarowymi. $\mathrm{Na}$ tej podstawie mogą interpretować wyniki i formułować wnioski. Ciągłość pomiarowa ogródka meteorologicznego daje również możliwość weryfikacji sprawdzalności wydanych prognoz dla miasta Poznania (wartości temperatury maksymalnej, temperatury minimalnej, opadu, przebiegu ciśnienia atmosferycznego).

\section{GLOBE - co szkoła może dać uczelni wyższej?}

Program GLOBE (Global Learning and Observations to Benefit the Environment) to międzynarodowy program badawczo-edukacyjny, którego celem jest popularyzacja metody naukowej wśród uczniów wszystkich typów szkół, kształtowanie świadomości ekologicznej i zaangażowanie w ochronę środowiska (Program GLOBE w Polsce 2018). Popularyzacja ta ma miejsce dzięki włączaniu uczniów różnych typów szkół do gromadzenia danych pomiarowych wybranych parametrów środowiska geograficznego (w tym parametrów meteorologicznych). Gromadzone dane, zgodnie z procedurą ujednoliconą dla wszystkich państw tworzących sieć pomiarową programu GLOBE, zapewnia porównywalność wyników między uczestnikami projektu. W Polsce nad poprawnością procedur pomiarowych oraz wartością merytoryczną projektu czuwa Rada Naukowa Programu GLOBE, w skład której wchodzą specjaliści z poszczególnych dyscyplin naukowych, będących przedmiotem zainteresowania programu. Po raz pierwszy to uczniowie tworzą samodzielnie powiązanie sieciowe z uczelniami wyższymi (por. ryc. 2), dostarczając regularnych danych pomiarowych, które dzisiaj liczone są w milionach rekordów. Tylko w pierwszym półroczu 2018 r. ukazało się sześć publikacji naukowych, w których skorzystano $\mathrm{z}$ danych pomiarowych sieci GLOBE, w czasopismach o zasięgu międzynarodowym, m.in. „Research in Science Education”, „Connected Science Learning” czy „Open Journal of Geology” (Publications, 2018). 


\section{PODSUMOWANIE}

Realizacja program „Łejery! Co to za pogoda?!”, opartego na włączeniu w proces kształcenia wybranych podmiotów - biznesu, uczelni, IMGW, stanowi przykład budowy sieci uczącej się w myśl konektywistycznej teorii kształcenia. Wykorzystanie przyszkolnych ogródków meteorologicznych może prowadzić do zwiększenia zainteresowania uczniów meteorologią, a w konsekwencji geografią. Możliwość prowadzenia regularnych pomiarów i obserwacji wspomaga proces kształcenia i umożliwia realizację ogólnych celów kształcenia geograficznego i przyrodniczego w szkole podstawowej. Dostępność uczniów do profesjonalnej aparatury umożliwia wsparcie innego węzła sieci uczącej się - uniwersytetu przez dostarczanie danych pomiarowych. Dane te są wykorzystywane w naukowych opracowaniach, co dodatkowo świadczy o aplikacyjnym charakterze realizacji projektu. Dzięki nawiązaniu współpracy różnych środowisk możliwe stało się kształtowanie wybranych kompetencji, w tym umiejętności krytycznego myślenia, twórczego rozwiązywania problemów, kompetencji uczenia się czy pracy zespołowej. Zgromadzenie długiej serii pomiarowej pozwala na wykorzystanie w przyszłości danych także w ramach innych przedmiotów - matematyki (w celach statystycznych) czy informatyki (w celach wizualizacji zgromadzonych danych pomiarowych).

\section{LITERATURA}

Czachorowski S., 2017: Tydzień cudów, czyli „Co tam, panie, w szkołach stychać?”, <http://czachorowski.blox.pl/html/page/4.html> [dostęp: 29.08.2017].

Downes S., 2017: Podtacz się, [w]: Ł. Badowski (red.), Konferencja Pokazać-Przekazać-Konektywizm: zamiast wędki dajmy sieć, <http://www.kopernik.org.pl/fileadmin/user_upload/ PROJEKTY_SPECJALNE/Konferencja_Pokazac-Przekazac/Edycja_2017/PP_2017_Publikacja_PP.pdf` $>$ [dostęp: 4.02.2018].

Dylak S., 2013: Architektura wiedzy w szkole, Wyd. Difin, Warszawa.

Frankowski M., 2015: Czy konektywizm jest szansa polskiej edukacji?, <http://www.cen.uni.wroc. pl/Pliki/Wydawnicza/21_wybrane_teksty/06_fanki.pdf> [dostęp: 7.01.2018].

Klus-Stańska D., 2000: Konstruowanie wiedzy w szkole, Wyd. Uniwersytetu Warmińsko-Mazurskiego, Olsztyn.

Program GLOBE w Polsce, <http://globe.gridw.pl/globe-w-polsce/program-globe-w-polsce> [dostęp: 16.03.2018].

Publications, <https://blog.globe.gov/web/guest/do-globe/publications/2016-2020> [dostęp: 24.05.2018].

Rocard report 2007, Science Education Now: A New Pedagogy for the Future of Europe, $<$ https:// www.eesc.europa.eu/sites/default/files/resources/docs/rapportrocardfinal.pdf $>$ [dostęp: 10.01.2018].

Rozporządzenie Ministra Edukacji Narodowej z dnia 14 lutego 2017 r. w sprawie podstawy programowej wychowania przedszkolnego oraz podstawy programowej kształcenia ogólnego dla szkoły podstawowej, w tym dla uczniów z niepełnosprawnością intelektualną w stopniu umiarkowanym lub znacznym, kształcenia ogólnego dla branżowej szkoły I stopnia, kształce- 
nia ogólnego dla szkoły specjalnej przysposabiającej do pracy oraz kształcenia ogólnego dla szkoły policealnej, <http://www.dziennikustaw.gov.pl/DU/2017/356> [dostęp: 25.02.2018].

Rundgren C.J., 2017: Implementation of inquiry-based science education in different countries: some reflections, Cult. Stud. of Sc. Educ., 1-9.

Siemens G., 2005: Connectivism: A learning theory for the digital age, Internat. Journ. of Instructional Technol. and Dist. Learning, 2(1), 3-10.

Tkocz J., 2008: Podstawy geografii społeczno-ekonomicznej: wykład teoretyczny, Wyd. Uniwersytetu Śląskiego, Katowice, 13-58.

WMO, 2015: Manual on the WMO Information System, World Meteorological Organization. 